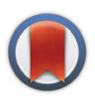

CrossMark

\& click for updates

Cite this: Dalton Trans., 2015, 44 6288

Received 13th December 2014,

Accepted 12th February 2015

DOI: 10.1039/c4dt03831b

www.rsc.org/dalton

\section{Location of $\mathrm{Ge}$ and extra-framework species in the zeolite ITQ-24†}

\author{
A. B. Pinar, ${ }^{\star a}$ L. B. McCusker, ${ }^{a}$ C. Baerlocher, ${ }^{a}$ J. Schmidt, ${ }^{\text {b }}$ S.-J. Hwang, ${ }^{\text {b }}$ M. E. Davis ${ }^{\text {b }}$ \\ and S. I. Zones ${ }^{\mathrm{C}}$
}

The germanosilicate ITQ-24 (IWR framework type) was synthesized in fluoride medium using 1,3,5-tris(1,2-dimethylimidazolium) benzene as the structure directing agent (SDA). A structure analysis of the assynthesized ITQ-24 material using synchrotron powder diffraction data and difference electron density calculations have allowed the fluoride ions and the germanium atoms to be located and the conformation of the SDA to be determined. The benzyl ring is perpendicular to the $b$ axis with the three imidazolium moieties forming a "T-shaped" arrangement. Ge atoms replace some of the Si in the double-4-ring (d4r) and in one of the single-4-rings (s4r). The other $s 4 r$ contains only Si. Fluoride ions are in the $d 4 r$ units. Initially, the space group $\mathrm{Cmmm}$ (highest possible symmetry) was assumed, but the framework geometry was strained. An independent evaluation of the symmetry using the powder charge flipping algorithm in Superflip led to a successful refinement with reasonable geometry and a refined composition of $\left|\left[\left(\mathrm{C}_{6} \mathrm{H}_{3}\right)\left(\mathrm{C}_{7} \mathrm{H}_{10} \mathrm{~N}_{2}\right)_{3}\right]_{2} \mathrm{~F}_{2}\right|\left[\mathrm{Si}_{40.2} \mathrm{Ge}_{15.8} \mathrm{O}_{112}\right]$ in the space group Pban.

\section{Introduction}

Zeolite synthesis is a complex process that is only poorly understood in detail. ${ }^{1}$ Over the years, certain reagents in the synthesis gel have been identified as being structure directing, the prime one being the organic cation used. These are usually quaternary ammonium cations, around which the silicate species in the initial synthesis gel are thought to assemble. ${ }^{2}$ In efforts to create large pores in the final product, increasingly bulky cations have been investigated. ${ }^{3,4}$ It has been demonstrated in numerous syntheses in the last decade, that the inclusion of Ge in the synthesis mixture can have a profound effect on the crystalline product. ${ }^{5-10} \mathrm{~A}$ Ge atom, being larger and somewhat less rigid than $\mathrm{Si}$, allows some frameworks to form that would not crystallize in a pure silicate system. In particular, Ge has been found to favor the formation of double 4-ring $(d 4 r)$ units. ${ }^{11}$ This is normally assumed to be because $\mathrm{Ge}-\mathrm{O}-\mathrm{Ge}$ or $\mathrm{Si}-\mathrm{O}-\mathrm{Ge}$ bond angles can be smaller than can $\mathrm{Si}-\mathrm{O}-\mathrm{Si}$ angles, making it easier to accommodate the $d 4 \mathrm{r}$ geometry. Finally, the mineralizer, usually hydroxide or fluoride, can also play a structure directing role. ${ }^{5,12,13}$ The fluoride

\footnotetext{
${ }^{a}$ Laboratory of Crystallography, ETH Zurich, Zurich, Switzerland.

E-mail: ana.pinar@mat.ethz.ch

${ }^{b}$ California Institute of Technology, Pasadena CA 91125, USA

${ }^{c}$ Chevron ETC, Richmond CA, USA

$\dagger$ Electronic supplementary information (ESI) available: Crystallographic information file (CIF) for ITQ-24 and the ${ }^{29} \mathrm{Si}$ and ${ }^{19} \mathrm{~F}$ MAS NMR spectra. See DOI: $10.1039 / \mathrm{c} 4 \mathrm{dt} 03831 \mathrm{~b}$
}

route, for example, has proven to produce more perfect crystals and to favor the formation of $d 4 r$ units.

In this study, the structure directing efficacy of the triply charged triquat 1,3,5-tris(1,2-dimethylimidazolium) benzene (Fig. 1) was explored. A wide range of synthesis conditions in the presence of Ge and $\mathrm{HF}$, in both aluminophosphate and silicate systems were examined. Surprisingly, in all of these syntheses, only two types of crystalline products were found: zeolite A (framework type LTA $^{14}$ ) in the aluminophosphate system $^{15}$ and ITQ-24 (IWR) in the silicate one. The only obvious correlation between these two zeolite framework types is that both contain $d 4 r^{\prime}$ s. The latter is the subject of the present study.<smiles></smiles>

Fig. 1 The structure directing agent 1,3,5-tris(1,2-dimethylimidazolium) benzene. 
a

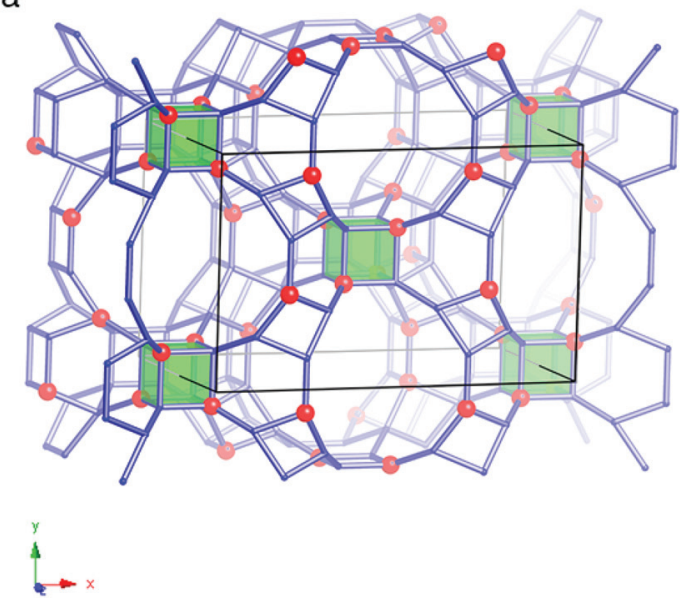

b

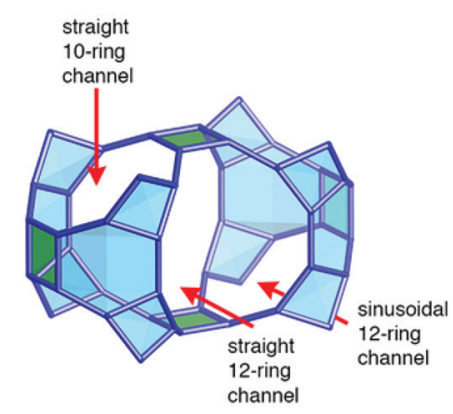

Fig. 2 The ITQ-24 framework structure showing (a) the arrangement of the $d 4 r$ units, and (b) the intersection of the three channels. A possible arrangement of $\mathrm{Ge}$ atoms (red) is shown in (a). Oxygen atoms have been omitted for clarity.

The synthesis and structure analysis of ITQ-24 were first reported by the Corma group in $2003 .{ }^{8}$ Their material was prepared in hydroxide media using hexamethonium as the structure directing agent (SDA). The framework structure, which proved to be that of the hypothetical polymorph $\mathrm{C}$ in the SSZ-33/SSZ-26/CIT-1 family of zeolite structures, ${ }^{16-18}$ was confirmed with a structure refinement using X-ray powder diffraction data collected on a calcined sample. Its IWR-type framework structure has a $12-\times 12-\times 10$-ring three-dimensional channel system with straight 12-ring channels running parallel to the $c$ axis, sinusoidal ones running parallel to the $a$ axis, and straight 10-ring channels running parallel to the $b$ axis (Fig. 2). The straight 12-ring channels are separated from one another by $d 4 r$ units. As might be expected, the Ge atoms in that material were found to be concentrated in the $d 4 r$. A later, more detailed study, showed that while the Ge atoms favor the $d 4 r$, they are also present in one of the two single 4-rings. ${ }^{19}$

Here we were interested in determining (1) how the bulky 1,3,5-tris(1,2-dimethylimidazolium) benzene SDA fitted into the IWR pore system, (2) where the fluoride ions were located, and (3) whether or not the Ge distribution was affected by the fact that a very different SDA had been used in the synthesis. To this end, a careful structure analysis of the as-synthesized material using synchrotron powder diffraction data was undertaken.

\section{Results and discussion}

\section{Results}

Synthesis and characterization. ITQ-24 was obtained after ca. 12 days of hydrothermal treatment at $175^{\circ} \mathrm{C}$. Thermogravimetric analysis of the material showed a weight loss of $18.1 \mathrm{wt} \%$ for the organic and fluoride (1.96 SDAs per unit cell, Fig. 3) and very low water content, as is usually observed for germano-

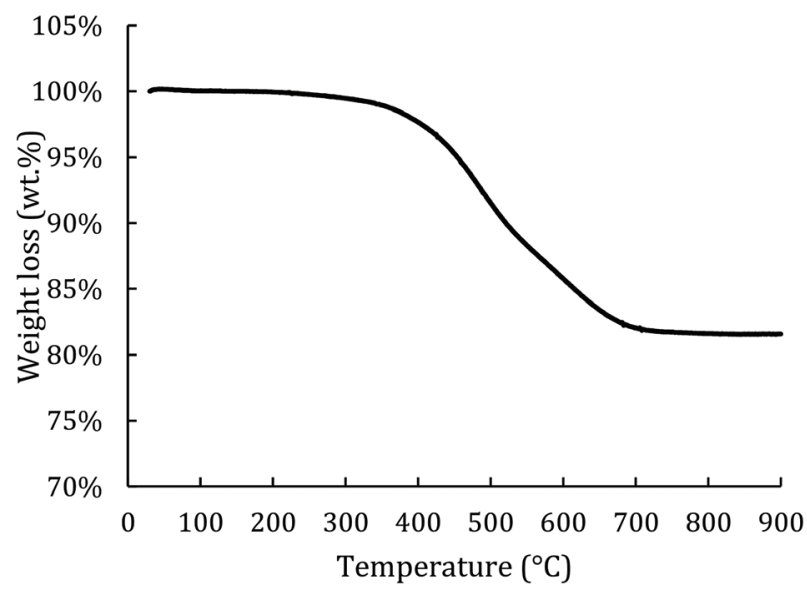

Fig. 3 TGA analysis of the sample ITQ-24.

silicate microporous materials synthesized in fluoride medium.

The integrity of the SDA after the hydrothermal treatment was assessed by ${ }^{13} \mathrm{C}$ NMR spectroscopy. All the signals observed in the liquid state ${ }^{13} \mathrm{C}$ MAS NMR spectrum of a solution containing the organic SDA are present in the spectrum of the as-made zeolite. This indicates that the SDA is intact within the zeolite (Fig. 4). The Si/Ge ratio in the crystalline product measured by EDX was found to be about 3.0 ( $c a .42 \mathrm{Si}$ and $14 \mathrm{Ge}$ atoms per unit cell). The $\mathrm{Si} / \mathrm{Ge}$ ratio of the synthesis gel is 2.0 , so apparently not all of the Ge was incorporated into the zeolite. Since the partial replacement of Si by Ge does not introduce any charge into the framework, the positive charge of the two organic SDA species per unit cell (total of 6 positive charges) must be balanced by extra-framework species. The $\mathrm{F} / \mathrm{N}$ ratio obtained from chemical analysis is 0.30 , which suggests that there is not enough fluoride to balance all the 


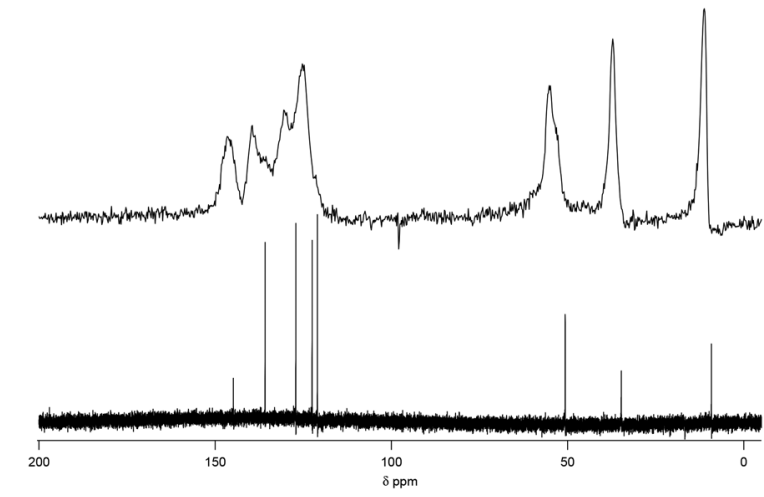

Fig. 4 Solid-state ${ }^{13} \mathrm{C}$ CP MAS NMR spectrum of as-made ITQ-24 (upper) compared to the spectrum of a solution containing the organic SDA cation (lower).

positive charges. They are probably compensated for by framework defects and/or hydroxide ions. The ${ }^{19} \mathrm{~F}$ MAS NMR has three main resonances at $-10.2,-21$, and $-51 \mathrm{ppm}$, and a negligible resonance at $-39 \mathrm{ppm}$ (Fig. $1 \mathrm{~S}$, Table $1 \mathrm{~S} \dagger$ ). Resonances at $-116.5,-120.2$ and $-126.3 \mathrm{ppm}$ are due to the presence of $\mathrm{SiF}_{6}{ }^{3-}$ species, and the resonance at $-85.6 \mathrm{ppm}$ cannot be assigned. In agreement with ${ }^{19} \mathrm{~F}$ NMR characterization of materials containing $d 4 r^{\prime}$ s the resonance at $-10.2 \mathrm{ppm}$ is assigned to fluoride anions in $d 4 r$ 's with a composition [4Si, $4 \mathrm{Ge}$. This is the most prominent signal and corresponds to the composition found in the refinement. The resonance at $-51 \mathrm{ppm}$ may correspond to fluoride anions located in Ge-containing $\left[4^{1} 5^{2} 6^{2}\right]$ cages, as was previously observed in Ge-ITQ-13. ${ }^{20}$ For pure silica cages, the signal shifted to $-66 \mathrm{ppm}$. These cages must contain Ge in the ITQ-24 sample, because all the $\mathrm{T}$ atoms, $\mathrm{T} 1-\mathrm{T} 7$, are present in the cage. The very weak signal at $-39 \mathrm{ppm}$ is assigned to a minor amount of fluoride in pure silica $d 4 r$ 's. The resonance at $-21 \mathrm{ppm}$ could correspond to fluoride occluded in $d 4 r$ 's that contain other amounts of germanium and silica. . $^{5,19,21-25}$

The ${ }^{29}$ Si MAS NMR spectrum of the as-made ITQ-24 sample (Fig. 2S, ESI $\dagger$ ) has very broad signals, as is normally observed for as-made germanosilicate zeolites. The resonances at -115.5 and $-110.8 \mathrm{ppm}$ are tentatively assigned to a $\mathrm{Si}(\mathrm{OSi})_{4}$ environment $-108.2 \mathrm{ppm}$ to $\mathrm{Si}(\mathrm{OSi})_{3}(\mathrm{OGe}),-104.4$ and $-101.0 \mathrm{ppm}$ to $\mathrm{Si}(\mathrm{OSi})_{2}(\mathrm{OGe})_{2}$ and $-93.8 \mathrm{ppm}$ to $\mathrm{Si}(\mathrm{OSi})-$ $(\mathrm{OGe})_{3}$. The signal at $-97.9 \mathrm{ppm}$ is attributed to defect $\mathrm{Si}(\mathrm{OSi})_{2}(\mathrm{OGe})^{-}$sites.

Scanning electron micrographs show that the ITQ-24 crystals have a rhombic prism morphology (Fig. 5).

\section{Structure analysis}

The diffraction pattern of ITQ-24 was indexed using the program TREOR $^{26}$ implemented in $\mathrm{CMPR}^{27}$ to give a C-centred orthorhombic unit cell ( $a=21.17, b=13.63, c=12.62 \AA)$, which is similar to that reported for the framework structure of ITQ-24 (framework type IWR) by Corma et al. ${ }^{8}$ Structure refinement was initiated in the space group $\mathrm{Cmmm}$ using the

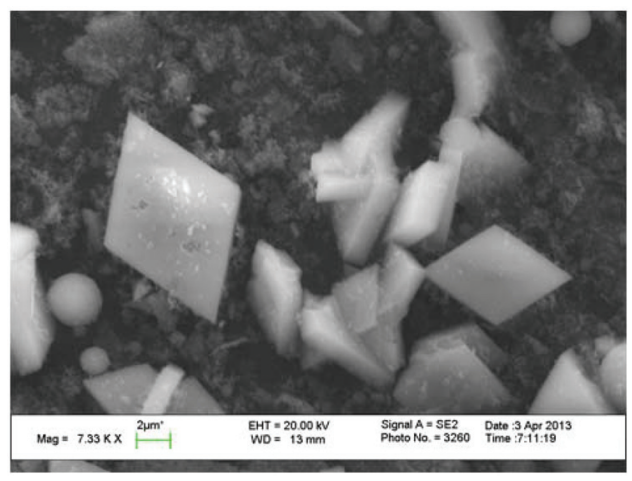

Fig. 5 Scanning electron microscopy image of the sample ITQ-24 showing the rhombic prism morphology.

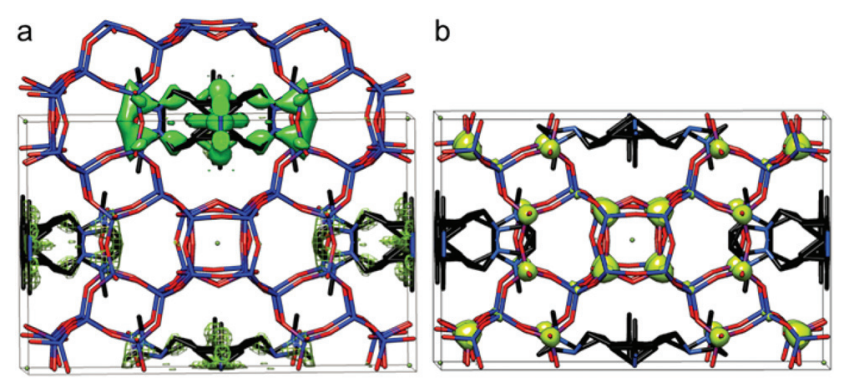

Fig. 6 Difference electron density map calculated in Cmmm (a) before adding the organic SDA to the model (one and a half unit cells are displayed to show the electron density for a complete molecule), and (b) before adding Ge to the model (SDA included). The final refined structure is overlaid for comparison.

published atomic coordinates. First the geometry was optimized using a distance-least-squares procedure, ${ }^{28}$ assuming all atoms in tetrahedral coordination ( $\mathrm{T}$ atoms) to be Si.

A difference electron density map then revealed the location and conformation of the SDA at the intersection of the straight 10- and 12-ring channels with the sinusoidal 12-ring channel (see Fig. 6). A certain amount of chemical interpretation was required, because the SDA does not have as high a symmetry as the framework, and as a consequence, it is disordered over four equivalent positions with equal probability (maximum occupancy of 0.25). However, it was possible to deduce that the benzyl ring was oriented perpendicular to the $b$ axis, with the three imidazolium moieties on one side of the ring forming a "T-shaped" arrangement around it. Two lie on the mirror plane perpendicular to $\mathrm{c}$ and are related to one another by the mirror plane perpendicular to a, and the third lies on the mirror plane perpendicular to $a$.

Only after the SDA had been added to the model did the electron density peaks corresponding to $\mathrm{Ge}$ appear in the difference electron density map (Fig. 6). Large peaks were observed on the $\mathrm{T}$ atoms of the double-four-ring $(d 4 r)$, and smaller peaks appeared on two of the $\mathrm{T}$ atoms in one of the 
two single-four-rings $(s 4 r)$. This additional electron density was interpreted to indicate the presence of $\mathrm{Ge}$ at those positions, so Ge was added, keeping the total $\mathrm{Ge}+\mathrm{Si}$ occupancy at each position at 1.0. This is consistent with the location of Ge found in other zeolites (e.g. ITQ- $7^{5}$, ITQ- $22^{9}$ and ITQ- $21^{10}$ ), where Ge also favors $d 4 r$ 's. No Ge was found in the second $s 4 r$.

Not surprisingly, a fluoride ion was found to occupy the center of each $d 4 r$, and its occupancy factor refined to one per $d 4 r$, or two per unit cell.

Refinement of this model with geometric restraints on the bond lengths and angles of both the organic and the framework yielded a reasonable geometry for the organic species, but the framework was strained. Large differences in the four $\mathrm{T}-\mathrm{O}$ distances from each $\mathrm{T}$ site, especially $\mathrm{T} 1$, were observed $\left(\begin{array}{ll}1.57-1.70 & \AA\end{array}\right)$. Furthermore, residual electron density was observed close to T3. In an attempt to obtain a better model for the framework and a cleaner difference electron density map, Ge and Si were refined independently, but this did not result in a better geometry.

At this point it was reasoned that the distorted geometry could be due to the fact that all the oxygen atoms in the $d 4 r$ lie on mirror planes, so one coordinate is always fixed. It was not clear which mirror plane should be removed, so an independent evaluation of the symmetry was carried out by running the powder charge flipping $(p C F)$ algorithm ${ }^{29}$ implemented in Superflip. ${ }^{30}$ In this program for structure solution from powder diffraction data, the algorithm does not assume any symmetry beyond the unit cell translational symmetry (it this case, C1), and once it has found a solution, it searches for the symmetry of the electron density map. The structure refined in $\mathrm{Cmmm}$ was used to calculate a phase set. These phases were then allowed to vary by up to $30 \%$ in a random fashion to create a new starting phase set for each $p C F$ run. The best of the resulting electron density maps suggested that at least one of the mirror planes was missing.

The symmetry was first reduced to $\mathrm{Cm} 2 \mathrm{~m}$, but the geometry did not improve. Then $\mathrm{Cmm} 2$ and $\mathrm{C} 222$ were tried, but with equally unsatisfactory results. Therefore, Pban, the highest primitive subgroup of $\mathrm{Cmmm}$ without any mirror planes, was tested. The asymmetric unit contains $7 \mathrm{~T}$ sites: $\mathrm{T} 1$ and $\mathrm{T} 2$ are in the $d 4 r$, T3-T6 in one $s 4 r$, and $\mathrm{T} 7$ in the other. Refinement of the framework in this symmetry finally led to a reasonable geometry and a clean difference electron density map. With this lower symmetry, however, the SDA suffered from pseudosymmetry effects. To reduce the resulting instability in refinement, the benzyl ring was forced to be planar (the $y$ coordinate was constrained to be the same for all six $\mathrm{C}$ atoms) as were the imidazole moieties. With these constraints added, the coordinates of the SDA atoms refined well. The $\mathrm{H}$ atoms in the SDA were taken into account by increasing the population factors of the $\mathrm{C}$ atoms according to the number of $\mathrm{H}$ atoms bonded to them. The occupancy for this model refined to 1.9 per unit cell, so it was set to 2 (the maximum). This is in very good agreement with the value obtained from the thermogravimetric analysis results (1.96 SDAs per unit cell). The structure of ITQ-24 with the SDA and fluoride ions included is shown in

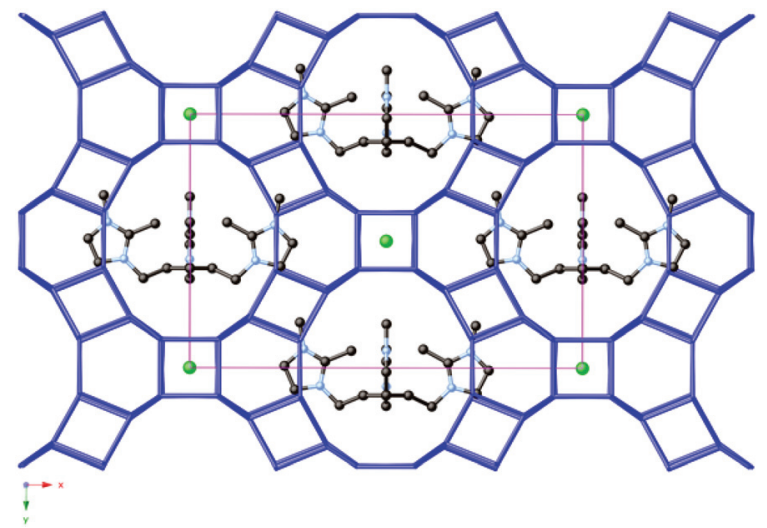

Fig. 7 View of the ITQ-24 framework down the $c$ axis. The organic species are located at the intersections between the 10- and 12-ring channels, and the fluoride atoms occupy the center of the $d 4 r$ 's. Oxygen atoms have been omitted for clarity.
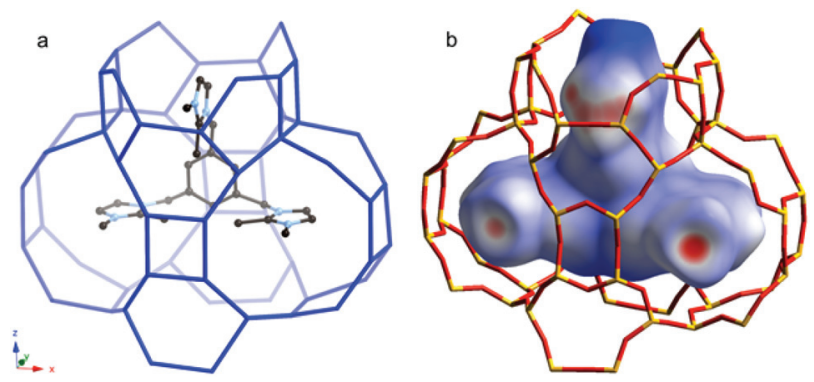

Fig. 8 Detail of the structure to show the T-shaped configuration of the 1,3,5-tris(1,2-dimethylimidazolium) benzene SDA. Oxygen atoms have been omitted for clarity (a). Hirshfeld surface (b) viewed down the $b$ axis calculated using CrystalExplorer. ${ }^{38} \mathrm{~A}$ contact distance normalized by the van der Waals radii of the atoms involved (dnorm) has been used. Red areas represent intermolecular contacts shorter than the sum of the van der Waals radii of the atoms. Distances around the sum of van der Waals radii are white and longer contacts are blue.

Fig. 7 and 8. The crystallographic data are given in Table 2, and the profile fit for this model is shown in Fig. 9.

\section{Discussion}

The structure of Ge-ITQ-24 synthesized in the presence of 1,3,5-tris(1,2-dimethylimidazolium) benzene adopts a symmetry (Pban) lower than that reported previously for calcined Ge-ITQ-24 $\left(\mathrm{Cmmm}^{6}\right.$ and $\left.\mathrm{Amm} 2^{19}\right)$. However, the published structure refined in $\mathrm{Cmmm}$ is strained with large differences in the four $\mathrm{T}-\mathrm{O}$ distances for two of the $\mathrm{T}$ sites. This is similar to our findings for refinements in $\mathrm{Cmmm}$ so a decrease in the symmetry in that case may also have resulted in more reasonable bond distances and angles. As might be expected, the SDA is located at the intersections of the three channels. The benzyl ring is oriented perpendicular to the $b$ axis and the three imidazolium moieties form a "T-shaped" arrangement 
Table 1 Synchrotron powder diffraction data collection parameters for the sample ITQ-24

Synchrotron facility Beamline

Diffraction geometry

Detector

Monochromator

Wavelength

Sample

Nominal step size

Detector positions

Time per pattern

$2 \theta$ range

\author{
SLS \\ Material science \\ Debye-Scherrer \\ MYTHEN II \\ Si 111 \\ $1.000 \AA$ \\ rotating $0.3 \mathrm{~mm}$ capillary \\ $0.004^{\circ} 2 \theta$ \\ $10 \mathrm{~s}$ \\ $4.0-44.0^{\circ} 2 \theta$
}

Table 2 Crystallographic data from the Rietveld refinement of ITQ-24

\begin{tabular}{|c|c|c|}
\hline Chemical composition & $\begin{array}{l}\left|\left[\left(\mathrm{C}_{6} \mathrm{H}_{3}\right)\left(\mathrm{C}_{7} \mathrm{H}_{10} \mathrm{~N}_{2}\right)_{3}\right]_{2} \mathrm{~F}_{2}\right| \\
{\left[\mathrm{Si}_{40.2} \mathrm{Ge}_{15.8} \mathrm{O}_{112}\right]}\end{array}$ & \\
\hline \multicolumn{3}{|l|}{ Unit cell } \\
\hline$a$ & $21.1443(1) \AA$ & \\
\hline$b$ & 13.6221(1) ̊ & \\
\hline$c$ & $12.6108(1) \AA$ & \\
\hline Space group & Pban & \\
\hline Standard peak $(h k l, 2 \theta)$ & $110,5.01^{\circ}$ & \\
\hline Peak range (FWHM) & 15 & \\
\hline Data points & 10240 & \\
\hline Contributing reflections & 750 & \\
\hline Geometric restraints & 218 & \\
\hline $\mathrm{T}-\mathrm{O}^{b}$ & $1.61-1.69(1) \AA$ & 28 \\
\hline $\mathrm{O}-\mathrm{T}-\mathrm{O}$ & 109.5(20)A & 42 \\
\hline $\mathrm{T}-\mathrm{O}-\mathrm{T}^{c}$ & $135 / 145(8)^{\circ}$ & 15 \\
\hline $\mathrm{C}-\mathrm{N}^{d}$ & 1.36/1.45(1) Å & 18 \\
\hline $\mathrm{C}-\mathrm{C}^{e}$ & 1.54/1.40(1) А̊ & 15 \\
\hline $\mathrm{C}-\mathrm{N}-\mathrm{C}$ & $109.8(20)^{\circ}$ & 6 \\
\hline $\mathrm{C}-\mathrm{C}-\mathrm{C}$ & $120.0(20)^{\circ}$ & 12 \\
\hline $\mathrm{C}-\mathrm{C}-\mathrm{N}^{f}$ & $106.8 / 111.4 / 125.8(20)^{\circ}$ & 15 \\
\hline $\mathrm{N}-\mathrm{C}-\mathrm{N}$ & $112.0(20)^{\circ}$ & 3 \\
\hline \multicolumn{3}{|l|}{ Parameters } \\
\hline Structural & 130 & \\
\hline Profile & 9 & \\
\hline$R_{\mathrm{F}}$ & 0.123 & \\
\hline$R_{\mathrm{wp}}$ & 0.122 & \\
\hline$R_{\exp }$ & 0.019 & \\
\hline
\end{tabular}

${ }^{a}$ The numbers given in parentheses are the esd's in the units of the least significant digit given. Each restraint was given a weight equivalent to the reciprocal of its esd. ${ }^{b}$ The $\mathrm{T}-\mathrm{O}$ bond distance restraint was adjusted to reflect the Ge population at each $\mathrm{T}$ site. ${ }^{c}$ The $\mathrm{T}-\mathrm{O}-\mathrm{T}$ bond angle restraint was set to 135 for those angles with at least one $\mathrm{T}$ site partially occupied by Ge. ${ }^{d}$ The $\mathrm{C}-\mathrm{N}$ bond distance restraint was set to 1.36 for $\mathrm{N}-\mathrm{CH}_{2}$ in the imidazolium moiety and to 1.45 for all others. ${ }^{e}$ The $\mathrm{C}-\mathrm{C}$ bond distance restraint was set to 1.54 for $\mathrm{CH}-\mathrm{CH}_{3}$ and $\mathrm{CH}-\mathrm{CH}_{2}$, and to 1.40 for $\mathrm{CH}_{2}-\mathrm{CH}_{2}$ and $\mathrm{CH}-\mathrm{CH}$ bonds. ${ }^{f}$ The $\mathrm{C}-\mathrm{C}-\mathrm{N}$ bond angle restraint was set to 106.8 for $\mathrm{N}-\mathrm{CH}_{2}-\mathrm{CH}_{2}$, 111.4 for $\mathrm{N}-\mathrm{CH}_{2}-\mathrm{CH}$ and 125.8 for $\mathrm{N}-\mathrm{CH}-\mathrm{CH}_{3}$ bonds.

around it. It fills almost all of the void volume available. This is reflected in the Hirshfeld surface ${ }^{31}$ shown in Fig. 8, where the two round red spots indicate a close packing of the organic molecules along the $b$ axis. The elongated red spot is due to a short distance $(2.9 \AA)$ between one of the methyl groups and a framework oxygen atom. This short contact, also observed for two of the methylene groups that link the benzyl ring to an imidazole moiety, may be indicative of weak $\mathrm{CH}$... O inter-

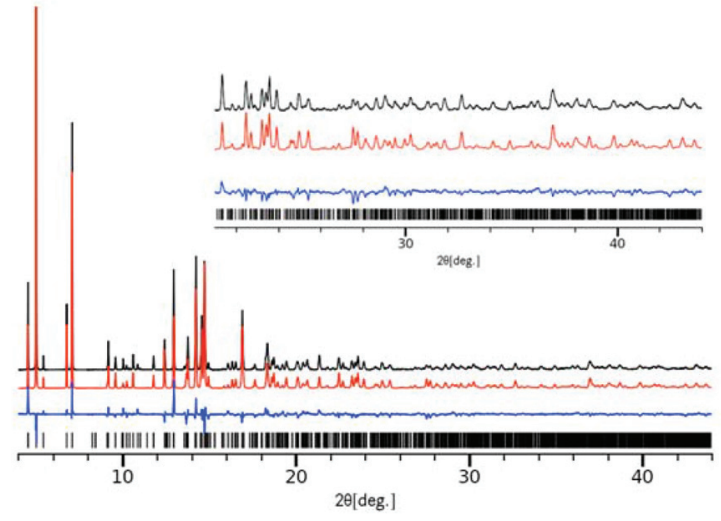

Fig. 9 Observed (black), calculated (red) and difference (blue) profiles for the Rietveld refinement of ITQ-24. The profiles in the inset have been scaled up by a factor of 3.5 to show more detail. Reflection positions are marked as vertical bars.

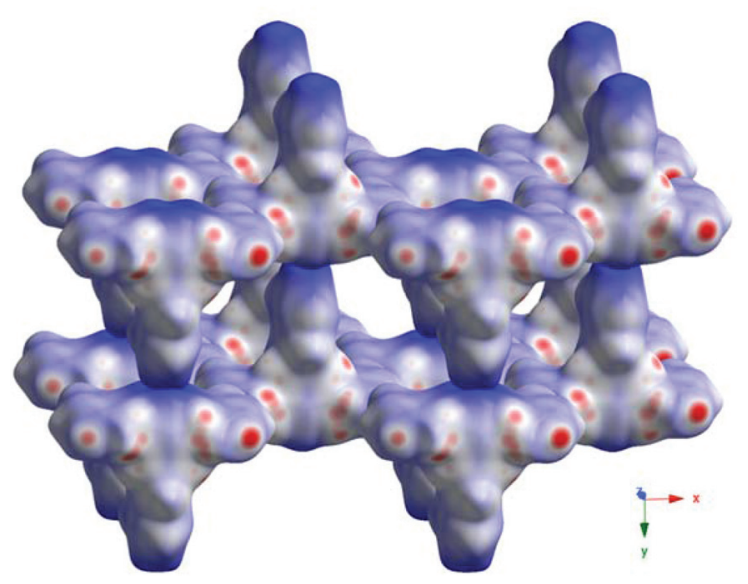

Fig. 10 View of the Hirshfeld surface down the $c$ axis to show the efficient packing of the SDA species within the channels of ITQ-24. Colors are as in Fig. 8.

actions. An overall view of the Hirshfeld surfaces (Fig. 10) shows the efficient packing of the SDA species, which have arranged themselves to mimic the channel system of the zeolite. The occupancy factors refined to 1.9 SDAs per unit cell, which is consistent with the thermogravimetric analysis results. The charge-balancing fluoride ions were the only other extra-framework species located. In view of the TGA results, water molecules were not expected.

A fluoride ion was found to occupy the center of each $d 4 r$ to give a total of two per unit cell. The results from chemical analysis showed that the amount of fluorine is $c a$. $3.6 \mathrm{~F} / \mathrm{u}$.c., so there is some unlocalized fluoride that could correspond to the signals at -51 or $-85.6 \mathrm{ppm}$ in the ${ }^{19} \mathrm{~F}$ NMR spectrum, or to $\mathrm{SiF}_{6}{ }^{3-}$ species (Fig. $2 \mathrm{~S}$, ESI $\dagger$ ). The signal at $-51 \mathrm{ppm}$ that could be assigned to fluoride occluded in Ge-containing $\left[4^{1} 5^{2} 6^{2}\right]$ cages $^{20}$ is very broad, probably because the fluoride is 
Table 3 Average refined T-O bond distance and percentage of $\mathrm{Ge}$ in each T site for ITQ-24

\begin{tabular}{llll}
\hline T site & $\mathrm{T}^{-\mathrm{O}_{\text {avg }}}$ & $\mathrm{Ge} \mathrm{PP}^{a}$ & Ge/u.c. \\
\hline $\mathrm{T} 1$ & 1.66 & $49 \%$ & 3.9 \\
$\mathrm{~T} 2$ & 1.67 & $51 \%$ & 4.1 \\
$\mathrm{~T} 3$ & 1.62 & $16 \%$ & 1.4 \\
$\mathrm{~T} 4$ & 1.60 & - & - \\
$\mathrm{T} 5$ & 1.67 & $59 \%$ & 4.7 \\
T6 & 1.63 & $23 \%$ & 1.8 \\
T7 & 1.59 & - & -
\end{tabular}

${ }^{a} \%$ of Ge in each T site. The $\%$ of $\mathrm{Si}$ is $100-\% \mathrm{Ge} .{ }^{b}$ Ge atoms per unit cell in each $\mathrm{T}$ site. The number of $\mathrm{Si}$ atoms is 8 minus the number of Ge atoms.

disordered over several positions. This would be consistent with the fact that it could not be located in the structure analysis. The amount of fluoride found in the chemical analysis is not enough to balance all six positive charges from the two organic cations per unit cell. The remaining charges must be balanced either by unlocated $\mathrm{OH}^{-}$groups and/or by framework defects $\mathrm{Si}-(\mathrm{OSi})_{2}(\mathrm{OGe}) \mathrm{O}^{-}$. The latter would be consistent with the ${ }^{29} \mathrm{Si}$ NMR spectrum.

The Ge atoms are distributed over 5 of the $7 \mathrm{~T}$ sites (see Fig. 2a). One of the four $\mathrm{T}$ sites in one $s 4 r$ is pure $\mathrm{Si}$ (T4), and the average composition of the ring is $[3 \mathrm{Si}, 1 \mathrm{Ge}]$, with the Ge showing a preference for T5 (59\%), over T6 and T3 (23 and $17 \%$, respectively). The second $s 4 r$ has a pure Si composition (T7). In the $d 4 r$, the two $\mathrm{T}$ sites $\mathrm{T} 1$ and $\mathrm{T} 2$ refined to 49 and $51 \% \mathrm{Ge}$, respectively. In other words, the average composition of the $d 4 r$ is $\left[4 \mathrm{Si}, 4 \mathrm{Ge}\right.$ ]. The ${ }^{29} \mathrm{Si}$ MAS NMR spectrum (Fig. 2S, ESI $\dagger$ ) is consistent with this structure. This distribution of Ge is similar to that of ITQ-24 with the same Ge content refined in Amm2. ${ }^{19}$ However, in that case the Ge populations in the $\mathrm{T}$ sites that are equivalent in $\mathrm{Cmmm}$ were constrained to be equal. In the refinement in Pban significant differences between the Ge populations in those equivalent positions are observed (T3 and $\mathrm{T} 4$ are $16 \%$ and $0 \%$, respectively, and T5 and T6 59\% and 23\%). These details are lost in the higher symmetry. The refined composition of the framework is thus $\mathrm{Si}_{40.2} \mathrm{Ge}_{15.8} \mathrm{O}_{112}$, with a Ge content slightly higher than that found in the chemical analysis $\left(\mathrm{Si}_{42} \mathrm{Ge}_{14} \mathrm{O}_{112}\right)$. The $\mathrm{T}-\mathrm{O}$ bond distances and $\mathrm{T}-\mathrm{O}-\mathrm{T}$ bond angles reflect the Ge populations, i.e. the mixed $\mathrm{Ge} / \mathrm{Si}$ positions with a higher percentage of Ge have longer $\mathrm{T}-\mathrm{O}$ distances (see Table 3) and smaller $\mathrm{T}-\mathrm{O}-\mathrm{T}$ bond angles. The Ge distribution is similar to that reported previously for calcined Ge-ITQ-24 samples synthesized in hydroxide medium with hexamethonium as the SDA. ${ }^{6}$

\section{Experimental section}

\section{Synthesis}

Synthesis of the SDA. All the reagents were purchased from Sigma-Aldrich and used without further purification. The triquat 1,3,5-tris(1,2-dimethylimidazolium) benzene was synthesized following the procedure described in ref. 32 and 33 . To ensure its purity, the product was recrystallized in absolute ethanol, and dried under vacuum. Its identity was verified by ${ }^{1} \mathrm{H}$ and ${ }^{13} \mathrm{C}$ liquid NMR (1H-NMR (500 MHz, $\left.\mathrm{D}_{2} \mathrm{O}\right): \delta 2.56$ (s, 9H), 3.81 (s, 9H), 5.37 (s, 3H), 7.18 (s, 3H)., $7.33(\mathrm{~d}, 3 \mathrm{H})$, $7.40(\mathrm{~d}, 3 \mathrm{H}) ;{ }^{13} \mathrm{C}-\mathrm{NMR}\left(125 \mathrm{MHz}, \mathrm{D}_{2} \mathrm{O}\right): \delta$ 9.86, 35.47, 51.38, $121.67,123.19,127.83,136.54,145.52)$. The bromide salt of the SDA was subsequently transformed into the corresponding hydroxide (SDAOH) using Supelco Dowex Monosphere 550A UPW hydroxide exchange resin with an exchange capacity of $1.1 \mathrm{meq} \mathrm{mL}^{-1}$. If necessary, the resulting solution was concentrated using rotary evaporation and the final solution was titrated with $0.01 \mathrm{M} \mathrm{HCl}$ using a Mettler-Toledo DL22 autotitrator.

Synthesis of the zeolite. ITQ-24 was synthesized from gels with molar composition: $0.67 \mathrm{SiO}_{2}: 0.33 \mathrm{GeO}_{2}: 0.5 \mathrm{R}_{1 / 3} \mathrm{OH}: 0.5$ $\mathrm{HF}: x \mathrm{H}_{2} \mathrm{O}, x=4-14$. Tetraethylorthosilicate (TEOS, $98 \mathrm{wt} \%$ ) and germanium ethoxide (99.95 wt\%) were added to an aqueous solution of the organic SDAOH. The container was closed and stirred overnight to allow for complete hydrolysis of Si and Ge sources. The lid was then removed and the ethanol and appropriate amount of water were allowed to evaporate under a stream of air. Once the appropriate mass was reached, the material was transferred to a Teflon Parr Reactor, and hydrofluoric acid (48 wt $\%$ in $\mathrm{H}_{2} \mathrm{O}, \geq 99.99 \%$ trace metals basis) added. The mixture was stirred by hand until a homogenous gel was obtained. The autoclave was sealed and placed in a rotating oven $(43 \mathrm{rpm})$ at $175^{\circ} \mathrm{C}$. Aliquots of the material were taken periodically by first quenching the reactor in water and then removing enough material for powder X-ray diffraction analysis.

Characterization. The crystalline products were identified using X-ray powder diffraction data (Rigaku MiniFlex II, $\mathrm{Cu} \mathrm{K} \alpha$ radiation). The organic content was characterized by thermogravimetric analysis (TGA) (PerkinElmer STA 6000), heating the samples up to $900{ }^{\circ} \mathrm{C}$ at a rate of $10{ }^{\circ} \mathrm{C} \mathrm{min}^{-1}$ ). The crystal morphology was determined by scanning electron microscopy (ZEISS 1550 VP FESEM, equipped with in-lens SE). EDX spectra were acquired with an Oxford X-Max SDD X-ray Energy Dispersive Spectrometer system. ${ }^{13} \mathrm{C}$ CP-MAS solid-state NMR spectra were recorded on Bruker DSX-200 spectrometer $(4.7 \mathrm{~T})$ with a Bruker $7 \mathrm{~mm}$ MAS probe at a spectral frequency of $50.29 \mathrm{MHz}$ at a rotation rate of $4000 \mathrm{~Hz}$ and were referenced relative to adamantane as an external standard $(2 \mathrm{~ms}$ contact time, 2 s delay). ${ }^{19} \mathrm{~F}$ NMR were recorded on a Bruker DSX-500 spectrometer $(11.7 \mathrm{~T})$ with a Bruker $4 \mathrm{~mm}$ MAS probe at a spectral frequency of $470.7 \mathrm{MHz}$ and was referenced relative to $\mathrm{CFCl}_{3}$ as an external standard ( $4 \mu \mathrm{s} 90^{\circ}$ pulse, $30 \mathrm{~s}$ delay). ${ }^{19} \mathrm{~F}$ MAS NMR were collected at both 13 and $15 \mathrm{kHz}$ to assign spinning side bands. ${ }^{1} \mathrm{H}$ and ${ }^{13} \mathrm{C}$ liquid NMR spectra were collected in a $400 \mathrm{MHz}$ Varian Spectrometer.

Structural analysis. Synchrotron powder diffraction data were collected on the Materials Science Beamline at the Swiss Light Source (SLS) in Villigen, Switzerland ${ }^{34}$ (Table 1). Rietveld refinement was performed using the XRS-82 suite of pro- 
grams. $^{35}$ The structure drawings were produced using CrystalMaker $^{36}$ and the profile plots with the program ppp $14 .{ }^{37}$

\section{Conclusion}

The finer details of the structure of the germanosilicate ITQ-24 (IWR) synthesized in fluoride medium using 1,3,5-tris(1,2dimethylimidazolium) benzene hydroxide as the SDA have been examined. Rietveld refinement has revealed that the bulky cations are located in the intersection of the 10- and 12ring channels, with the benzyl ring oriented perpendicular to the $b$ axis and the three imidazolium moieties all on one side of the ring in a "T-shaped" arrangement. Two fluoride ions per unit cell occupy the centers of the $d 4 r$ 's. This corresponds to slightly less than the amount of fluoride in the chemical analysis, and it is assumed that some ( 0.6 per unit cell) disordered fluoride ions are present, perhaps in the $\left[4^{1} 5^{2} 6^{2}\right]$ cages. The remaining positive charge of the SDA cations is balanced by framework defects and/or unlocated hydroxide ions. Ge atoms replace half of the $\mathrm{Si}$ in the $d 4 r$ and one quarter of those in the $s 4 r$ sites to yield average compositions of [4Si,4Ge] and [3Si,1Ge], respectively. The other $s 4 r$ in the framework contains only Si. This is consistent with the ${ }^{29} \mathrm{Si}$ MAS NMR spectrum. This distribution of Ge is similar to that reported for calcined ITQ-24 synthesized using the hexamethonium cation as the SDA in hydroxide medium (refined in the space group $\mathrm{Cmmm}$ ), so the arrangement does not appear to be influenced by the presence of fluoride ions or the nature of the SDA. The more reasonable bond distances and angles found in this study are probably the result of the fact that a lower space group (Pban) was used for the refinement.

\section{Acknowledgements}

The authors thank Nicola Casati and Antonio Cervellino from the Material Science beamline at SLS in Villigen, Switzerland, for their assistance with the powder diffraction measurement. A.B.P. thanks Chevron ETC for financial support.

\section{References}

1 C. S. Cundy and P. A. Cox, Microporous Mesoporous Mater., 2005, 82, 1.

2 A. Burton and S. I. Zones, Stud. Surf. Sci. Catal., 2007, 168, 137.

3 S. I. Zones, Y. Nakagawa, L. T. Yuen and T. V. Harris, J. Am. Chem. Soc., 1996, 118, 7558.

4 J. Sun, C. Bonneau, A. Cantín, A. Corma, M.-J. DíazCabañas, M. Moliner, D. Zhang, M. Li and X. Zou, Nature, 2009, 458, 1154.

5 G. Sastre, J. A. Vidal-Moya, T. Blasco, J. Rius, J. L. Jorda, M. T. Navarro, F. Rey and A. Corma, Angew. Chem., Int. Ed., 2002, 41, 4722 .
6 A. Corma, M.-J. Diaz-Cabanas, J. Martinez-Triguero, F. Rey and J. Rius, Nature, 2002, 418, 514.

7 A. Corma, F. Rey, S. Valencia, J. L. Jordá and J. Rius, Nat. Mater., 2003, 2, 493.

8 R. Castaneda, A. Corma, V. Fornes, F. Rey and J. Rius, J. Am. Chem. Soc., 2003, 125, 7820.

9 G. Sastre, A. Pulido, R. Castañeda and A. Corma, J. Phys. Chem. B, 2004, 108, 8830.

10 T. Blasco, A. Corma, M.-J. Diaz-Cabanas, F. Rey, J. Rius, G. Sastre and J. A. Vidal-Moya, J. Am. Chem. Soc., 2004, 126, 13414.

11 An n-ring in a zeolite framework structure consists of $\mathrm{n}$ tetrahedral nodes (e.g. Al, $\mathrm{Si}$ or $\mathrm{P}$ ) bridged by $n \mathrm{O}$ atoms. A double 4-ring or $d 4 r$ consists of two 4-rings connected via $\mathrm{O}$ atoms to form a cube. Composite building units found in more than one framework type have been assigned three letter codes (italic small letters), which are listed in ref. 14 .

12 A. Corma, M. Puche, F. Rey, G. Sankar and S. J. Teat, Angew. Chem., Int. Ed., 2003, 42, 1156.

13 L. A. Villaescusa, P. A. Barret and M. A. Camblor, Angew. Chem., Int. Ed., 1999, 38, 1997.

14 C. Baerlocher, L. B. McCusker and D. H. Olson, in Atlas of Zeolite Framework Types, Elsevier, Amsterdam, 2007; C. Baerlocher and L. B. McCusker, Database of Zeolite Structures http://www.iza-structure.org/databases/.

15 J. E. Schmidt, S. I. Zones, D. Xie and M. E. Davis, Microporous Mesoporous Mater., 2014, 200, 132.

16 S. I. Zones, US Pat, 4,963,337, 1990.

17 R. F. Lobo, M. Pan, I. Chan, H. X. Li, R. C. Medrud, S. I. Zones, P. A. Crozier and M. E. Davis, Science, 1993, 262, 1453.

18 S. I. Zones, D. S. Santilli, J. N. Holtermann, T. A. Pecorano and R. A. Innes, US Pat, 4,910,006, 1990.

19 J. L. Jorda, A. Cantin, A. Corma, M.-J. Diaz-Cabanas, S. Leiva, M. Moliner, F. Rey, M. J. Sabater and S. Valencia, Z. Kristallogr., 2007 (Suppl. 26), 393.

20 J. A. Vidal-Moya, T. Blasco, F. Rey, A. Corma and M. Puche, Chem. Mater., 2003, 15, 3961.

21 T. Blasco, A. Corma, M.-J. Díaz-Cabañas, F. Rey, J. A. VidalMoya and C. M. Zicovich-Wilson, J. Phys. Chem. B, 2002, 106, 2634.

22 G. Sastre, A. Pulido and A. Corma, Chem. Commun., 2005, 2357.

23 Y. Wang, J. Song and H. Gies, Solid State Sci., 2003, 5, 1421.

24 N. Kasian, A. Tuel, E. Verheyen, C. E. A. Kirschhock, F. Taulelle and J. A. Martens, Chem. Mater., 2014, 26, 5556.

25 X. Liu, U. Ravon, F. Bosselet, G. Bergeret and A. Tuel, Chem. Mater., 2012, 24, 3016.

26 P. E. Werner, L. Eriksson and M. Westdahl, J. Appl. Crystallogr., 1985, 18, 367.

27 B. H. Toby, J. Appl. Crystallogr., 2005, 38, 1040.

28 C. Baerlocher, A. Hepp and W. M. Meier, DLS-76, a FORTRAN program for the simulation of crystal structures by geometric refinement, Institut für Kristallographie und Petrographie, ETH Zürich, Switzerland, 1978. 
29 C. Baerlocher, L. B. McCusker and L. Palatinus, Z. Kristallogr., 2007, 222, 47.

30 L. Palatinus and G. Chapuis, J. Appl. Crystallogr., 2007, 40, 786.

31 M. A. Spackman and D. Jayatilaka, CrystEngComm, 2009, 11, 19.

32 J. Howarth and N. Al-Hashimy, Tetrahedron Lett., 2001, 42, 5777.

33 V. Patinec, P. A. Wright, R. A. Aitken, P. Lightfoot, S. D. J. Purdie, P. A. Cox, et al., Chem. Mater., 1999, 11, 2456.

34 P. R. Willmott, D. Meister, S. J. Leake, M. Lange, A. Bergamaschi, M. Boege, M. Calvi, C. Cancellieri, N. Casati, A. Cervellino, Q. Chen, C. David, U. Flechsig,
F. Gozzo, B. Henrich, S. Jaeggi-Spielmann, B. Jakob, I. Kalichava, P. Karvinen, J. Krempasky, A. Luedeke, R. Luescher, S. Maag, C. Quimann, M. L. Reinle-Schmitt, T. Schmidt, B. Schmitt, A. Streun, I. Vartiainen, M. Vitins, X. Wang and R. Wullschleger, Synchrotron Radiat., 2013, 20, 667.

35 C. Baerlocher and A. Hepp, XRS-82. The X-ray Rietveld System, Institut für Kristallographie, ETH Zürich, Switzerland, 1982.

36 CrystalMaker Software Ltd., UK, http://www.crystalmaker. com.

37 J. Graesslin, Ph.D. Thesis, ETH Zurich, 2013.

38 J. J. McKinnon, D. Jayatilaka and M. A. Spackman, Chem. Commun., 2007, 3814. 